\title{
Age-Related Effects of the Nicotinic Antagonist Mecamylamine on Cognition and Behavior
}

Paul A. Newhouse, M.D., Alexandra Potter, B.A., June Corwin, Ph.D., and Robert Lenox, M.D.

Studies of the neurochemical pathology of Alzheimer's disease and Parkinson's disease reveal a severe and specific loss of central nicotinic cholinergic receptors. We have investigated the functional significance of this finding for cognitive functioning by studying the effects of the centrally active nicotinic antagonist mecamylamine. Single oral doses of mecamylamine were administered to 12 healthy young males and 15 healthy elderly subjects in doses of 5, 10, and $20 \mathrm{mg}$ in a placebo-controlled, double-blind study. In both groups, the 20-mg dose caused a significant increase in errors in the learning condition of the Repeated Acquisition Task, producing a slower acquisition curve. There was no effect of drug on the performance component (retrieval of previously learned information). However, elderly subjects showed enhanced sensitivity to mecamylamine, with 10-mg dose producing significant impairment of learning not seen in the young normals. On a recognition memory task, there was an age-associated shift in response bias, with the elderly subjects becoming more liberal with increasing dose. Reaction-time measures suggested a dose-related slowing of reaction time on several tasks. Behavioral effects were minimal and physiologic effects were consistent with dose-related ganglionic blockade. These results indicate that acute blockade of nicotinic receptor function can produce measurable and significant cognitive impairment similar to some deficits seen in dementing illnesses, and that there is an age-related increase in sensitivity to nicotinic blockade. [Neuropsychopharmacology 10:93-107, 1994]
KEY WORDS: Mecamylamine; Nicotinic receptors; Aging; Learning; Alzheimer's disease

Although a myriad of neurochemical deficits have been described in Alzheimer's disease (AD), explanations of the nature of the cognitive disturbances have been most closely focused on the "cholinergic hypothesis," which implicates disturbances in central muscarinic choliner-

From the Clinical Neuroscience Research Unit, Department of Psychiatry (PAN, AP, RL), University of Vennont College of Medicine, Burlington, Vermont; and the Department of Psychiatry (JC), NYU School of Medicine and Department of Veteran's Affairs Medical Center, New York, New York.

Address correspondence to: Paul A. Newhouse, M.D., Clinical Neuroscience Research Unit, Department of Psychiatry, University of Vermont College of Medicine, 1 South Prospect Street, Burlington, Vermont 05401.

Received August 6, 1993; revised October 25, 1993; accepted November 7, 1993. gic mechanisms in normal cognitive functioning and disorders of memory function (Drachman and Leavitt 1974; Drachman 1977; Bartus et al. 1982; Whitehouse et al. 1982). More recently, it has become apparent that patients suffering from AD and Parkinson's disease (PD) also have a marked reduction in cortical nicotinic cholinergic receptor binding compared to age-matched controls (Flynn and Mash 1986; Whitehouse et al. 1986; Perry et al. 1987; Giacobini 1990). However, the functional significance of this receptor loss for the cognitive disorder associated with these diseases is uncertain.

In animals, nicotine facilitates task acquisition and memory consolidation (Nelson and Goldstein 1972; Nordberg and Bergh 1985), has been shown to improve delayed match-to-sample performance in monkeys (Elrod et al. 1988), and to reverse the effects of nucleus basalis lesions in the rat (Ksir and Benson 1983). In humans, nicotine is reported to increase arousal and at- 
tention as well as to decrease reaction time, prevent decline in efficiency over time, and improve the ability to withhold inappropriate responses (Wesnes and Warburton, 1983). In pilot studies (Newhouse et al. 1988b, 1990), we have shown that intravenous nicotine produces small but measurable improvements in several cognitive tasks in AD patients. Recently, Jones and colleagues (1992) have shown that acutely administered nicotine can improve attention and speed of information processing in $\mathrm{AD}$ patients. These results suggest that central nicotinic cholinergic systems are important in human cognitive functioning and may be involved in the cognitive symptomatology of dementias such as $\mathrm{AD}$ and PD.

The use of a cholinergic antagonist has been successful in evaluating the role of muscarinic systems in cognition using agents such as scopolamine (Sunderland et al. 1989) and atropine (Higgins et al. 1989). The use of antagonists that have a high degree of specificity allows the identification of cognitive operations affected by the interruption of agonist neurotransmission. Furthermore, cognitive deficits that follow drug administration of antagonists can be compared to those of specific cognitive disorders such as $\mathrm{AD}$ to evaluate the clinical significance of certain neurochemical defects. Although it would be overly simplistic to attempt to model the whole range of cognitive pathology of a complex neurodegenerative disorder with a single antagonist, the effects may indicate which cognitive domains are influenced by lesions to the affected system (Weingartner et al. 1987).

The memory problems of early AD have been conceptualized as difficulties in the storage of new information. There is a gradient such that memory deficits become more prominent as task difficulty increases: that is, as increasing organization and rehearsal of information is needed for efficient storage and retrieval. This conceptualization has led to the hypothesis that as $\mathrm{AD}$ progresses, the internal representations of information become increasingly degraded or "noisy" such that it becomes harder to locate, store, and retrieve information (Nebes et al. 1986; Grober et al. 1993). Related to this disorganization is that $\mathrm{AD}$ patients develop a liberal response bias on yes/no recognition and identification tasks (Corwin 1992; Snodgrass and Corwin 1988; Brandt et al. 1992). This defect appears characteristic of $A D$ and may be related to the well-known tendency of $A D$ patients to make high numbers of intrusion errors (Fuld et al. 1982). Overall, early deficits in AD might be most parsimoniously described as difficulties with new learning due to problems in organization and consolidation of information coupled with a noisy semantic memory system. The degree to which these deficits can be ascribed to particular neurochemical defects is unclear. However, these deficits in cognitive operations may be secondary to loss of central cholinergic innervation
(Sunderland et al. 1989) and may be influenced by nicotinic receptor modulation. The goal of this investigation was to further examine the effects of acutely impairing the nicotinic system on several of these cognitive processes.

These studies examined the effects of a temporary blockade of central nicotinic receptors by the drug mecamylamine on aspects of cognition. Mecamylamine is a centrally active noncompetitive antagonist of nicotine (and presumably acetylcholine) at C6 (ganglionic)type nicotinic receptors (Martin et al. 1989). Through its action on presumed presynaptic nicotinic receptors, mecamylamine appears to antagonize anticholinesterase-induced release of acetylcholine in vitro (Nordberg et al. 1989). Mecamylamine has also been shown to produce an increase in cigarette smoking (Stolerman et al. 1973; Pomerleau et al. 1987), to slow cortical EEG (Pickworth et al. 1988), and to block the positive effects of nicotine on learning in monkeys (Elrod et al. 1988). We have presented preliminary data suggesting that mecamylamine administered acutely to young healthy males produces impairment of several cognitive processes (Newhouse et al. 1992). Here, we present additional data from that experiment and report the results of additional studies in healthy elderly normal subjects of both sexes.

\section{METHODS}

\section{Subjects}

Twelve healthy young (mean age $23.9 \pm 5.0$ years, range 19 to 36 years) male volunteers and 15 healthy elderly (mean age $62.7 \pm 5.2$ years; seven males and eight females) volunteers participated in this study. Subjects were determined by interview, physical exam, and laboratory tests to be free of significant medical illness, psychiatric illness, or cognitive complaints. Elderly subjects were screened by a cognitive battery to ensure normal performance. The battery included the Mini Mental State exam and the Wechsler Memory Scale. Scores were required to be within the normal range. For the Mini Mental State exam, subjects had to have a score of 28 or greater. All subjects had at least a high school education and all were life-long nonsmokers.

\section{Cognitive Measures}

Pretesting training was done with each subject before each experiment to ensure stable asymptotic performance and minimize practice effects. All testing was done blind to drug dosage.

Repeated Acquisition Test. This procedure (RAT) allows the simultaneous measurement of a subject's abil- 
ity to retrieve previously acquired information as well as his/her ability to learn new information (Thompson 1973; Higgins et al. 1989). In this procedure, during training, a subject learns a sequence of button pushes on a three-button panel, with reinforcement provided by a computer (training phase). On study days, the subject performs under two different conditions (retrieval and learning). In the retrieval condition, the correct response sequence is always the same (the chain learned during training). In the learning condition, a new response sequence must be learned each time the task is done. During testing, the subject alternates between the retrieval and learning conditions. This allows the assessment of state changes on both new learning and recall of old learning almost simultaneously. For these experiments, all subjects were taught a 10-button sequence for both the retrieval and learning conditions. Measures obtained include sequenceerrors, quarter life, and total time for task completion. Quarter-life is defined as the trial by which one quarter of the errors are made.

Recognition Memory. The Hi-Lo Imagery Test (Corwin et al. 1987) is a word recognition memory test in which subjects are presented with 14 target words, seven each of high imagery ("cat") and low imagery ("idea"). Thereafter, subjects are tested with 28 words, the original 14 targets and 14 distractors (seven high and seven low imagery) and asked to indicate which words are old and new. Our testing consisted of two learning trials each followed immediately by a recognition trial with a subsequent delayed recognition trial approximately 15 minutes later. The task permits independent assessment of the course of acquisition and forgetting of the stimulus material (discrimination) and the performance behavior of the subject when he/she is uncertain (response bias).

Learning and Recall. The Selective Reminding task was used to test acquisition and retention by recall. This standard test has been widely used in studies of cognitiveimpairment and offers measures of storage into and retrieval from both short-term and long-term memory (Buschke and Fuld 1974). The test list consisted of 14 words. Measures obtained include total recall, recall consistency (a measure of how long words were held in memory unreinforced), and recall failure, defined as failing to recall a word after two successive reinforcements.

Psychomotor Ability. A Choice Reaction Time (CRT) task was used to assess overall psychomotor ability, accuracy, and speed of response. In this test, the numbers 0 to 9 appear sequentially on the screen, and the subject responds each time by pushing the matching number on a key pad. The interstimulus interval was 500 milliseconds. This test is a sensitive measure of at- tention, response time, and motor speed and is sensitive to the effects of drugs that affect attention, such as anticholinergics and stimulants (Thorne et al. 1985; Newhouse et al. 1989, 1992). A Manikin task was used as a test of spatial rotation. A human figure was presented in various orientations within a block or a circle, holding a smaller block or circle in one of its hands. The subject was asked to indicate which hand held the matching shape. Data obtained for both tasks included reaction time, number correct, and throughput, a speed-accuracy product that is a measure of useful work performed per unit time (Thorne et al. 1985).

\section{Behavioral Measures}

For observer ratings, the Brief Psychiatric Rating Scale (BPRS) (Overall and Gorham 1962) was used to measure psychopathologic behaviors. This scale appears to be sensitive to the behavioral changes induced by cholinergic drugs in both normals and AD patients (Sunderland et al. 1989). A battery of Visual Analog Scales (VAS) consisting of a series of items such as "drowsiness" or "psychomotor agitation" were scored on $100 \mathrm{~mm}$ lines by the experimenter. Subjects completed the National Institutes of Mental Health SelfRating scale (Van Kammen and Murphy 1975), VAS of self-report items rating aspects of mood, anxiety, alertness and physical comfort, and a physical symptom checklist.

\section{Physiologic Measures}

Vital signs were taken while the subject was recumbent at 30-minute intervals and included systolic (SBP) and diastolic (DBP) blood pressure, pulse, respiratory rate, and oral temperature. In addition, a test of the orthostatic effect of the drug was made at 160 minutes after drug administration. This test consisted of measuring pulse and BP before and after 5 minutes of standing.

\section{Drugs}

All drugs were administered double blind. The doses administered were 5,10 , and 20 mg of mecamylamine and placebo. These are doses both below and above that which produce a significant increase in smoking behavior and a measurable drop in BP (Stolerman et al. 1973; Pomerleau et al. 1987).

\section{Procedures}

There were 4 drug days, each separated by at least 48 hours. The drug sequence was random except that the largest dose $(20 \mathrm{mg})$ was not administered before at least one of the lower doses for safety reasons. Following 
an overnight fast, subjects were placed in bed in a recumbent position. The study began at 0730 hours with intravenous catheter insertion. At 0830 hours, baseline testing and evaluation were conducted. Drug was administered at 0900 hours. Repeat cognitive testing was conducted at +60 and +120 minutes, and behavioral measures obtained at $+60,+120$, and +180 minutes. The cognitive battery was administered on a Zenith 286 microcomputer (with the exception of the Selective Reminding task). The computer, keyboard, and button box were placed on an over-bed table, and subjects remained in bed sitting up during the testing. Vital signs and blood samples were obtained at 30-minute intervals. Subjects were followed for 240 minutes after drug administration before being discharged. Some older subjects experienced prolonged orthostatic hypotension and were retained on the research ward until the following morning.

\section{Data Analysis}

The general approach was that of a completely repeatedmeasures analysis of variance (ANOVA) or covariance (ANCOVA) (for variables that showed large day-to-day baseline differences) with dose, time, session, and trial as within-subjects repeated factors, age group as a between-subjects variable, and baseline as a covariate. Modified $F$ tests were used to adjust for correlated repeated measures (Vitaliano1982). Significant differential dose effects were inferred from a significant doseby-time interaction term. For the Buschke Selective Reminding Task, the components (total recall and consistency) were analyzed with trial as an additional within-factor. The CRT and the Manikin tasks were analyzed by examining the mean reaction time and number and types of errors. For the Hi-Lo Imagery test, dependent measures included estimates of discrimination and response bias calculated using the Two-High Threshold theory (Snodgrass and Corwin 1988), per imagery condition and trial.

\section{Results}

Cognitive measures are presented first, followed by behavioral and physiologic measures and clinical observations. Results are presented first for young normals, followed by old normals and intergroup comparisons. Results refer to the +120 -minute testing session unless otherwise indicated.

\section{COGNITIVE MEASURES}

\section{Repeated Acquisition}

Young Normals. Examination of the mean number of errors during the learning condition showed a signifi-

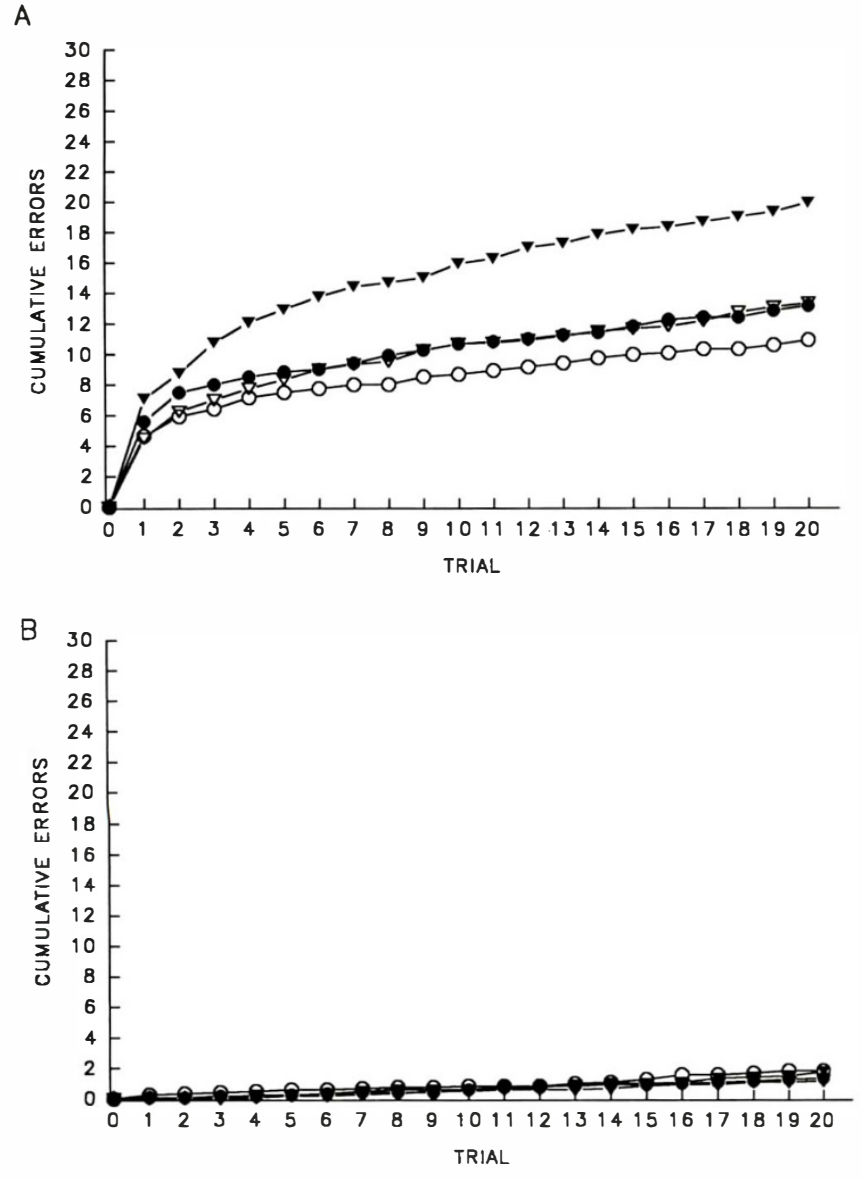

Figure 1. Repeated Acquisition Task: mean scores for young normals by trial for each dose at 120 minutes postdrug administration. $\mathbf{A}=$ Learning condition; $\mathbf{B}=$ Retrieval condition; $\boldsymbol{n}=12$. Open circle = placebo; filled circle $=5 \mathrm{mg}$; open triangle $=10 \mathrm{mg}$; filled triangle $=20 \mathrm{mg}$ mecamylamine .

cant dose by time interaction $(F[6,66]=2.53, p=.035)$, with the 20 -mg dose producing a larger number of total errors, which increased over trial (Fig. 1A). Examination of individual curves showed that after receiving $20 \mathrm{mg}$ of mecamylamine, subjects took longer to acquire the chain and generally had difficulty maintaining errorfree performance. There was a trend $(F[3,33]=2.6, p=$ .077) for a main effect for dose in the quarter-life statistic for the learning condition. The value tended to increase with increasing dose, suggesting impairment of acquisition. Under the retrieval condition, there was no effect of drug (Fig. 1B). There were no drug-related changes in response speed or total time taken for either condition.

Old Normals and Between-Group Comparisons. Analysis was restricted to the eight elderly subjects who were able to achieve the same baseline criterion performance as the young subjects. As with the young normals, mecamylamine produced a significant $(F[3,21]=4.74$, $p=.02)$ dose-related increase in errors in the learning 

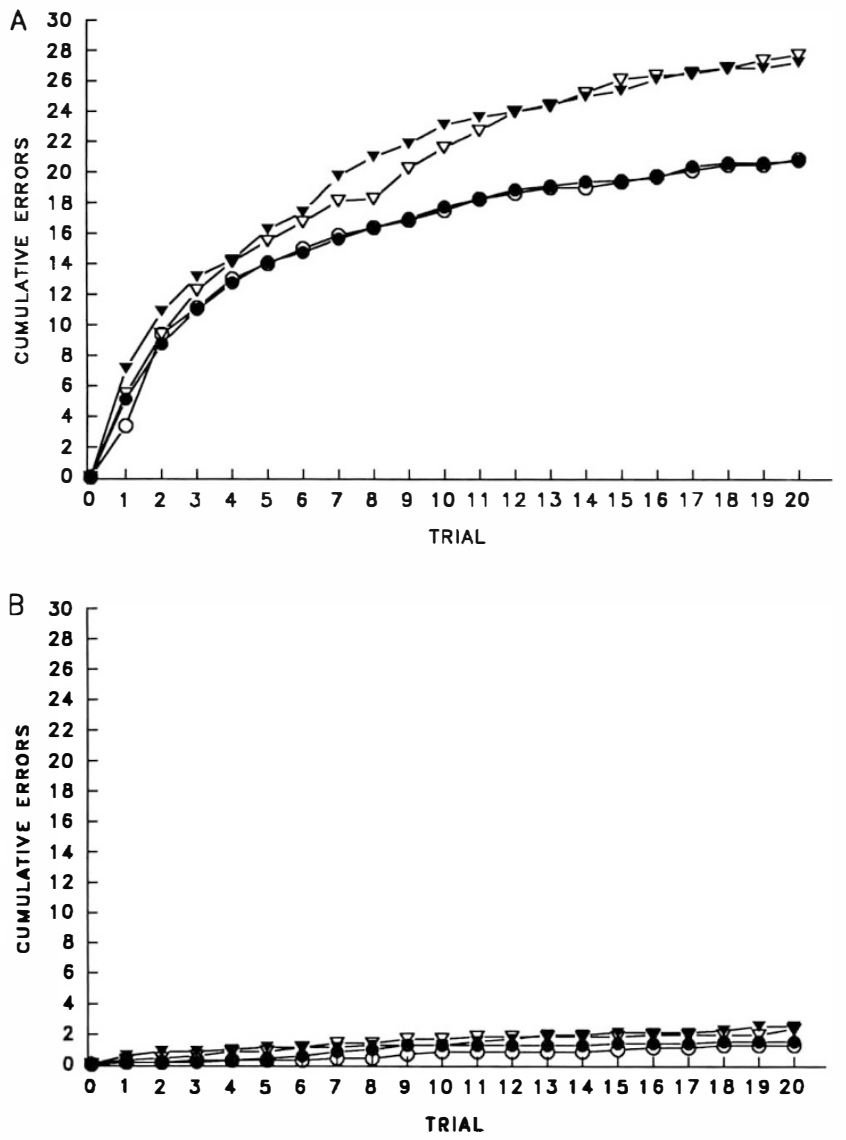

Figure 2. Repeated Acquisition Task: mean scores for old normals by trial for each dose at 120 minutes postdrug administration. $\mathbf{A}=$ Learning condition; $\mathbf{B}=$ Retrieval condition; $N=8$. Open circle = placebo; filled circle $=5 \mathrm{mg}$; open triangle $=10 \mathrm{mg}$; filled triangle $=20 \mathrm{mg}$ mecamylamine .

phase. However, in contrast to the young normals, both the 10- and 20-mg doses produced a similar number of errors, with cumulative errors being virtually identical for both doses by trial 20 (Fig. 2A). This effect was responsible for a significant $(F[3,54]=4.54, p=.017)$ dose-by-group interaction for total errors, indicating enhanced sensitivity in the old normal group. Evaluation of quarter-life during the learning phase again showed a trend $(F[3,21]=3.22, p<.97)$ for a dose-related increase with both 10 - and $20-\mathrm{mg}$ doses showing higher values than the 5-mg dose and placebo. Between-group comparisons for quarter-life showed a significant dose effect $(F[3,54]=6.32, p=.002)$ but no interaction with group, suggesting a similar magnitude of effect in both young and old.

Examination of speed was made by looking at responses per second during the learning phase. In addition to the large expected age effect, there was a significant dose effect $(F[3,54]=4.37, p=.032)$. Posthoc comparisons showed that the 20-mg dose produced a significantly $(p<.04)$ slower response time in both groups than did placebo, although the magnitude of the increase was greater in the older group $(100 \%$ versus $17 \%$ increase).

The retrieval chain showed no significant changes with drug in the old normal group (Fig. 2B). There was no significant age effect for total errors $(p>.3)$, and no dose-related effects on quarter-life. Similarly there were no group effects on either parameter.

\section{High-Low Imagery Task}

Young Normals. Total PR (discrimination) showed a trend toward a dose-by-trial interaction $(F[6.66]=2.55$, $p=.066$ ), with PR after the $20 \mathrm{mg}$ dose smaller than the placebovalue. Total response bias (BR) did not show a significant dose effect, but there was a significant $(F[6,66]=2.7, p<.03)$ dose-by-trial effect for highimagery words. There was a small decrease in BR that was evident at the second trial after the 5-mg dose only.

Old Normals and Between-Group Comparisons. There was a significant dose-by-session-by-trial interaction $(F[12,144]=1.98, p=.03)$, as well as a significant $(F[6,72]=2.22, p=.05)$ dose-by-trial effect on total PR, showing a dose-related impairment in learning. Comparison with the young normals showed a significant $(F[3,66]=3.4, p=.023)$ dose-by-age effect. Post-hoc analysis revealed that the elderly normals were impaired by both the 10 and the $20 \mathrm{mg}$ doses in their ability to learn from trial 1 to 2 , whereas the young normals showed a decline only on the 20-mg dose (Table 1). By contrast, both groups showed proportionately similar declines in PR following the delay period. For high-imagery words, there was a strong trend $(F[3,66]$ $=2.56, p=.06$ ) for a dose-by-age interaction, with

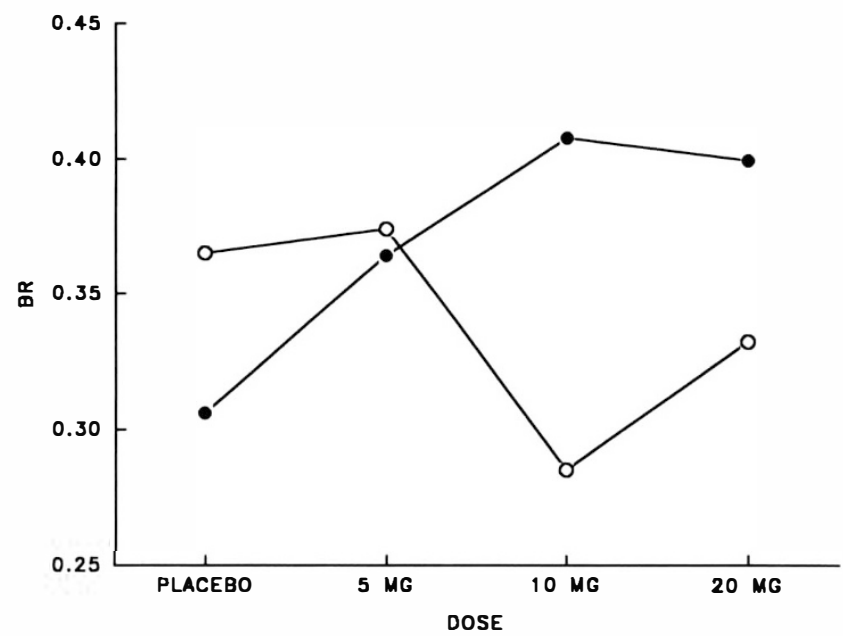

Figure 3. Hi-Low Imagery Task: BR for low-imagery words at 120 minutes postdrug administration (points represent mean of all trials). Open circles = young normals; filled circles $=$ old normals. 


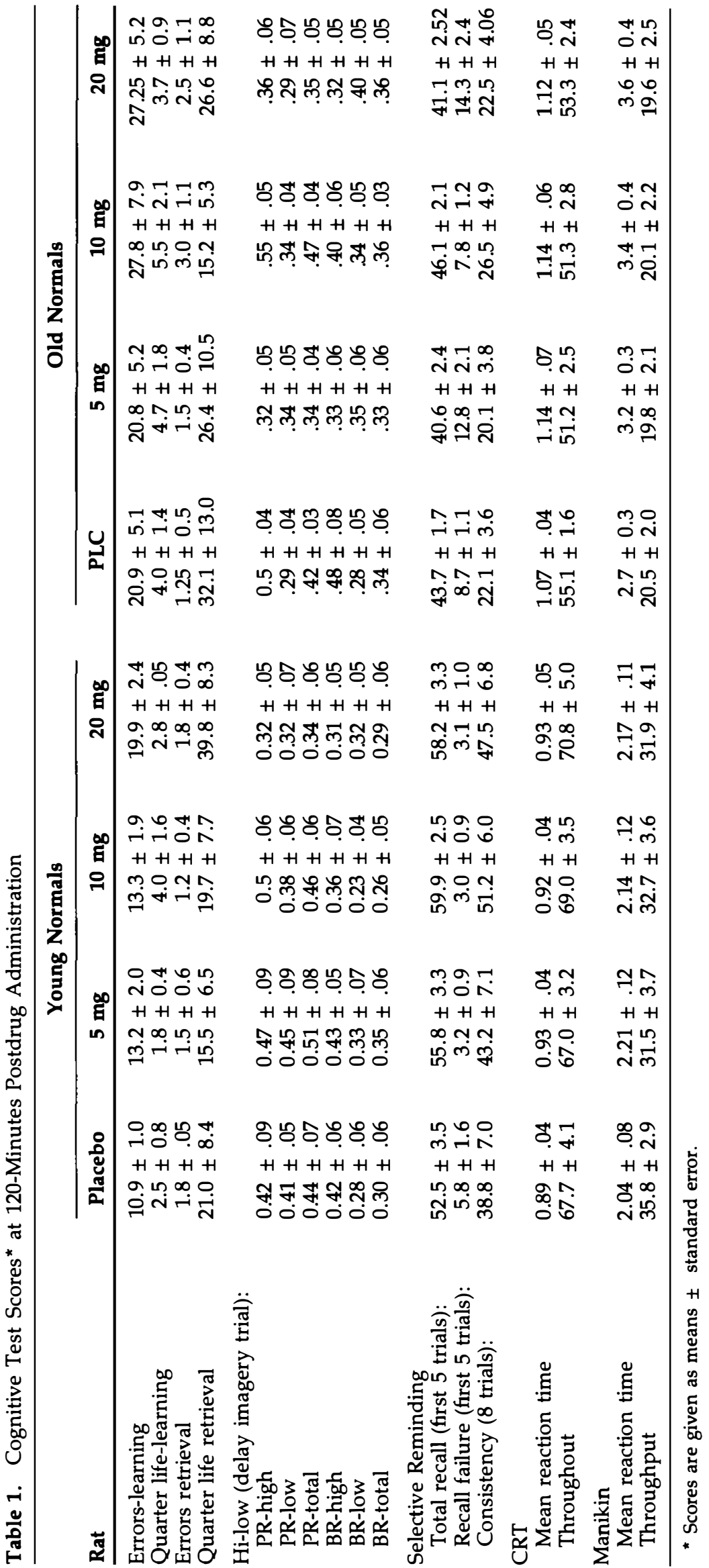


elderly normals showing a reduced increase in recognition on trial 2 following the $10-\mathrm{mg}$ dose compared to the young normals. Both groups showed a dose-related impairment in retention on the delay trial after $20 \mathrm{mg}$.

Response bias for low-imagery words showed a significant $(F[6,66]=2.4, p<.05)$ dose-by-session interaction with both 10 - and 20 -mg doses producing increasing liberal BR at 120 minutes. Comparisons with the young normals showed significant dose-by-sessionby-age interactions for total $\mathrm{BR}(F[6,132]=3.9, p=$ $.0013)$ and low-imagery $\operatorname{BR}(F[6,132]=2.37, p=.03)$. Figure 3 shows low-imagery BR plotted and reveals increasing probability of guessing "yes" with increasing dose in the elderly but not in the young normals.

\section{Choice-Reaction Time}

Young Normals. There was a significant $(F[6,60]=2.8$, $p=.018)$ dose-by-time interaction for overall mean reaction time as well as a similarly significant interaction for correct items $(p=.027)$. All doses produced slower reaction times than placebo (Table 1 ). There was no significant effect of drug on accuracy.

Old Normals and Between-Group Comparisons. There was a significant dose effect following ANCOVA $(F[3,35]=3.74, p=.02)$, with all three active doses showing reaction time slowing compared to placebo. Furthermore, there was a significant dose-by-time interaction for throughput $(F[6,72]=3.44, p=.005)$; the greatest decline in throughput occurred after the 10mg dose.

Comparing the groups, there was a significant $(F[3,69]=3.05, p=.047)$ dose-by-time-by-age interaction for mean reaction time. All doses of mecamylamine increased reaction time, although the increase was greater in the old normals. The young normals showed an increase in throughput with increasing dose (probably due to a speed-accuracy tradeoff), whereas the old normals were stable or showed a decline (Table 1).

\section{Manikin}

Young Normals. As with the CRT, there were signifcant dose-by-time interactions for the mean reaction time $(F[6,60]=2.8, p<.006)$, reaction time for correct responses $(p=.0015)$, and minimum reaction time $(p=$ $.019)$ with a dose-related slowing. There was no effect on accuracy or errors.

Old Normals and Between-Group Comparisons. There was a significant $(F[3,36]=3.14, p=.04)$ dose-by-time interaction for mean reaction time for correct responses with a linear dose-related slowing of reaction time. A similar effect $(F[3,36]=3.67, p=.036)$ was seen for maximum reaction time. Throughput showed a significant dose effect $(F[3,35]=4.33, p=.018)$, with all three active doses showing lower values than placebo.

Group comparisons showed no age-related effects. There was a significant $(F[3,66]=2.99, p=.037)$ doseby-time interaction for speed (1/reaction time) with both groups showing linear dose-related declines in speed with increasing dose. Similarly there was a dose-bytime interaction $(F[3,66]=2.81, p=.046)$ for throughput, with a small linear decrease across increasing dose for both groups.

\section{Selective Reminding}

Young Normals. There was a significant $(F[3,33]=3.4$, $p=.029$ ) main effect of dose on total recall with the 20mg dose producing significantly reduced recall across trials. However, the magnitude of the difference was small. There was no effect on memory consistency.

Old Normals and Between-Group Comparisons. There was a significant $(F[6,66]=4.94, p=.0009)$ dose-bysession effect for recall failure with a substantially higher recall failure following the $20-\mathrm{mg}$ dose.

Group comparisons showed a significant dose-byage interaction $(F[3,66]=3.91, p=.015)$ for recall failure. The older subjects showed a dose-related increase in recall failure, whereas the young normals did not (Fig. 4). There were significant main effects for dose on total recall $(F[3,75]=7.67, p=.0002)$ and consistency $(F[3,75]=5.54, p=.002)$ for the combined sample.

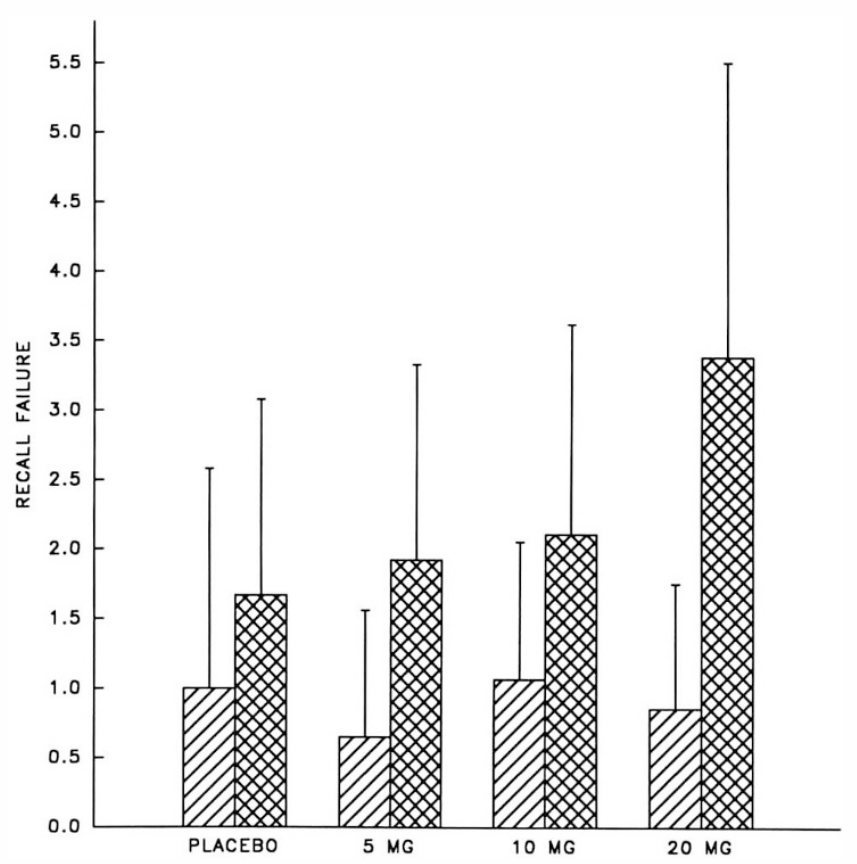

Figure 4. Selective Reminding Task: recall failure by dose and group at 120 minutes postdrug administration. Open bars = young normals; hatched bars = old normals. 


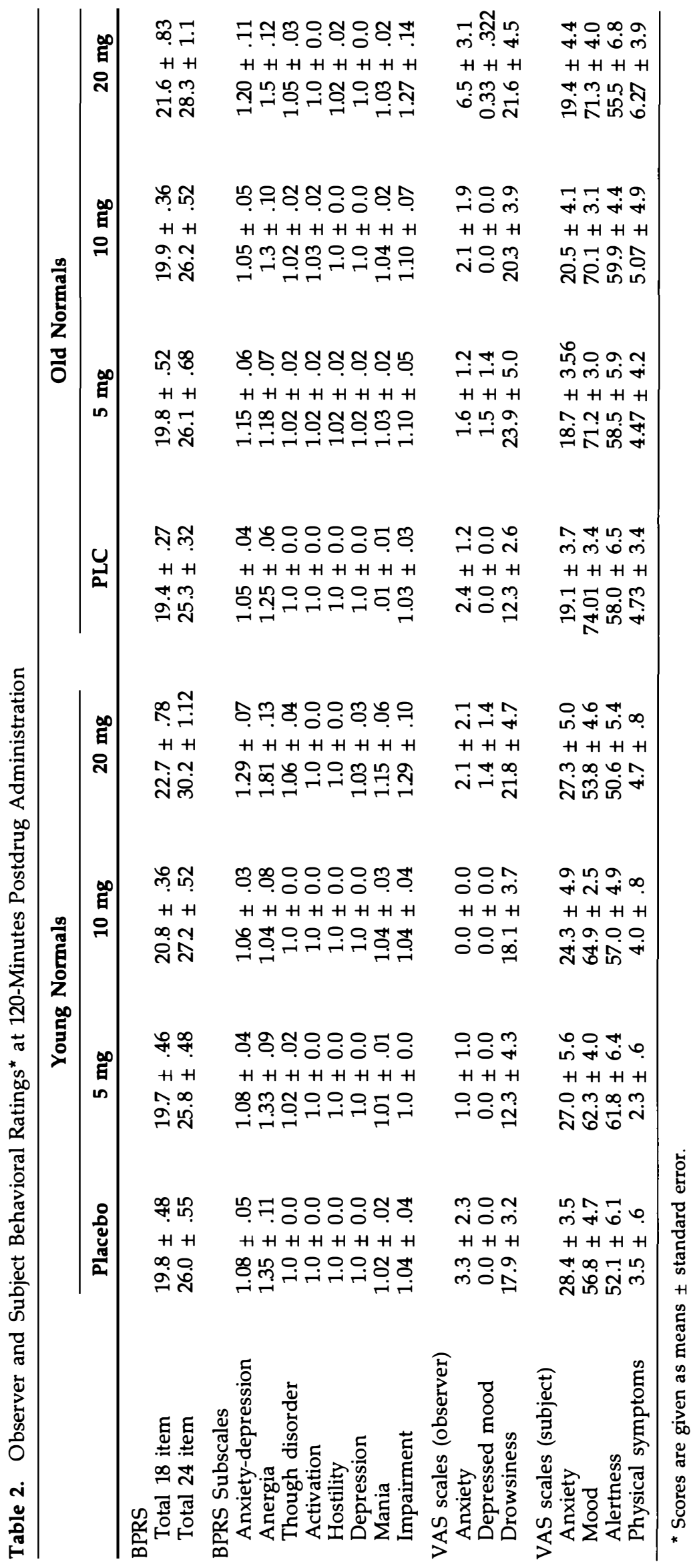




\section{BEHAVIORAL MEASURES}

\section{Young Normals}

Subject. After ANCOVA was performed to adjust for varying baseline values, no significant dose-by-time interactions appeared in any self-rating, and there were no main effects. Significantly, there were no changes in self-rated alertness, anxiety, or mood. The physical symptom checklist showed a trivial significant $(p=.006)$ time effect, but no dose effect or interaction.

Observer. For the VAS battery, fatigue showed a trend $(p<.06)$ towards a dose effect, but this effect appeared mainly due to the 5-mg dose, which had substantially lower ratings than the other two doses and placebo. For the BPRS, there were significant dose-by-time interactions for both the 18- $(F[9,99]=2.84, p<.009)$ and 24 -item $(p<.004)$ totals. However, the elevations were small and clinically insignificant (Table2). For subscales, there were statistically significant but clinically trivial dose-by-time interactions for the mania subscale $(p=$ $.011)$ and the activation scale $(p=.005)$. There was a significant main effect $(p=.008)$ for dose on the anergia subscale, with the 20 -mg dose producing slightly increased ratings.

\section{Old Normals and Between-Group Comparisons}

Subject. As with the young normals, no ratings showed significant dose-related changes. The physical symptom checklist showed no dose-related increases in total score.

Observer. No items from the VAS showed a significant dose-related increase. Similar to the young normals, the BPRS showed a significant dose-by-time interaction for the 18-item total $(F[6,84]=2.89, p=.04)$ with a strong trend for the 24-item total $(F[6,84]=2.62, p=$ .06 ). Totals after receiving the $20-\mathrm{mg}$ dose were somewhat greater (Table 2). Examination of subscale scores revealed significant dose-related elevation only on the anergia subscale $(F[6,84]=2.48, p=.046)$. The elevations were small and not clinically meaningful.

An ANCOVA combining groups revealed significant dose effects on the 24-item total $(F[3,71]=6.98$, $p=.0004)$, and the impairment $(p=.01)$, anxietydepression $(p=.02)$, and anergia $(p=.0006)$ subscales, with significant elevations being seen only after the 20 $\mathrm{mg}$ dose. There were no significant dose-by-age interactions.

\section{PHYSIOLOGIC MEASURES}

\section{Young Normals}

Mecamylamine produced a significant $(F[27,297]=5.4$, $p<.0001)$ dose-by-time interaction for pulse, with a dose-related increase in pulse rate (Table 3 ). This pulse rise began approximately 60 minutes after drug administration and persisted through the end of the study. There was no significant effect on BP. Oral temperature also showed a significant $(F[15,165]=2.85, p=$ $.001)$ dose-by-time interaction, with both the 10 - and 20-mg doses abolishing the normal temperature rise. A test of the orthostatic BP and pulse change showed that there was a significant dose effect on DBP $(p=$ $.015)$, with the 20-mg dose essentially abolishing the rise normally seen after 5 minutes of standing. Pulse also showed a significant $(p=.003)$ dose effect.

\section{Old Normals and Between-Group Comparisons}

There were significant dose-by-time interactions for SBP $(F[24,336]=2.73, p=.0004)$, pulse $(F=2.89, p=.001)$, oral temperature $(F[15,165]=2.38, p=.011)$, and pupil diameter $(F[12,108]=3.81, p=.0025)$. There was a main effect of dose $(F[3,42]=5.86, p=.002)$ on DBP. Mecamylamine produced a dose-related decline in SBP, $\mathrm{DBP}$, and oral temperature and produced a dose-related increase in pulse and pupil diameter (Table 3). Examination of the orthostatic BP test showed that there was significant dose-related reductions in $\operatorname{DBP}(F[3,30]=$ $4.79, p=.014)$ and pulse rise $(F=2.94, p=.049)$.

Comparing the groups, there was a significant dose-by-age-by-time interaction for $\operatorname{SBP}(F[27,594]=$ $1.93, p=.008$ ) and a significant dose-by-age interaction for DBP $(F[3,66]=3.41, p=.02)$. Similarly, there were significant dose-by-age interactions for the orthostatic BP test on DBP $(F[3,69]=2.65, p=.05)$ and pulse $(F=7.67, p=.0002)$. Older individuals showed a greater effect of mecamylamine on cardiovascular parameters and were significantly impaired in their ability to maintain BP and pulse when challenged with orthostatic challenge (Fig. 5).

\section{Clinical Observations}

As the behavioral ratings indicated, the observable effects of the drug were very mild. Subjects did occasionally complain of feeling "fuzzy" or slowed on the 10- or 20-mg dose, although not all were accurate in distinguishing their doses. Several subjects on the 20-mg dose noted persistent mild cognitive effects for some hours after the completion of the protocol. For some of the older subjects, significant orthostatic hypotension (asymptomatic unless standing) persisted for up to 8 hours following the $20-\mathrm{mg}$ dose. For those subjects, it was necessary to maintain them at bed rest until BP recovered.

\section{DISCUSSION}

In this investigation, the nicotinic antagonist mecamylamine produced cognitive impairment on several tasks. 


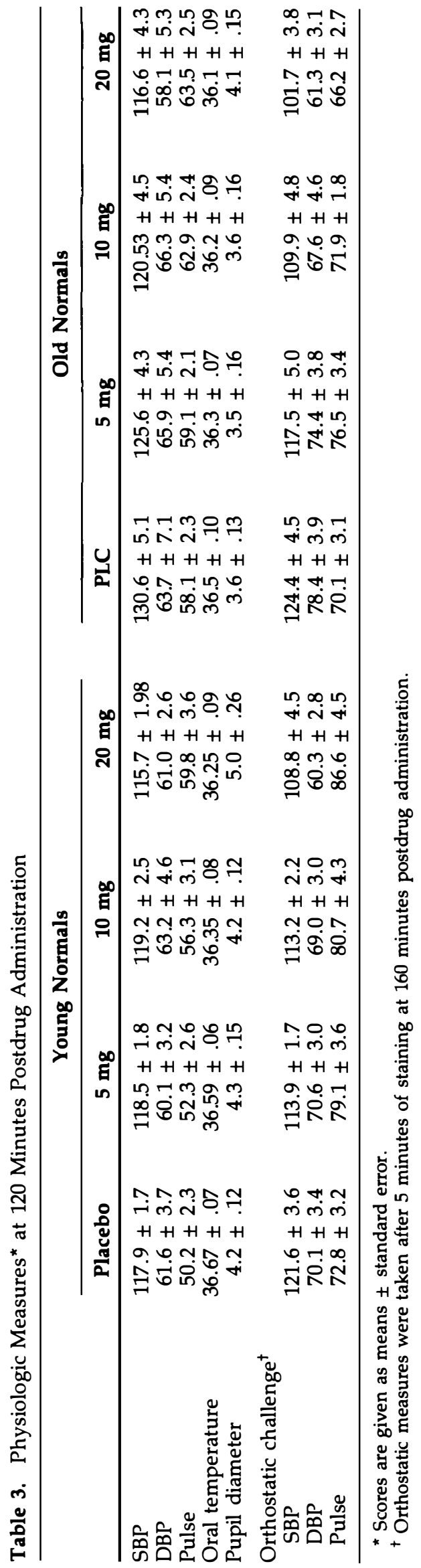



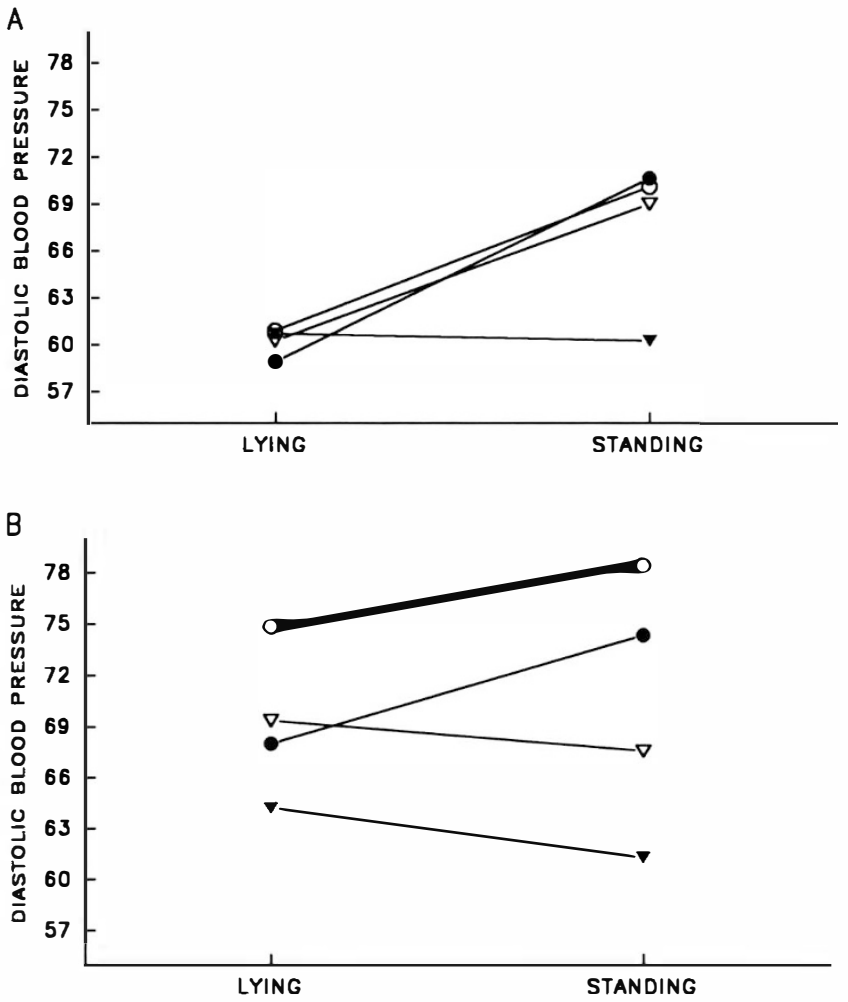

Figure 5. Orthostatic challenge test: DBP after 5 minutes of standing. $\mathbf{A}=$ young normals; $\mathbf{B}=$ old normals. Open circle = placebo; filled circle $=5 \mathrm{mg}$; open triangle $=10 \mathrm{mg}$; filled triangle $=20 \mathrm{mg}$ mecamylamine.

These effects included impairment of acquisition on the RAT task, impaired recall on the Selective Reminding task, slowing of reaction time, and impairment of PR and liberalization of $\mathrm{BR}$ on the $\mathrm{Hi}$ - Low Imagery task. Furthermore, there was evidence that elderly normals were proportionately more sensitive to the effects of mecamylamine. The lack of clinically significant behavioral changes and physical side-effects suggests that the cognitive effects were secondary to specific blockade of nicotinic receptors and not due to nonspecific effects on arousal or overall well-being. Here, we review the effects on task performance and explore the possible mechanisms involved. Second, we discuss the significance of these data for the role of nicotinic receptors in the neurobiology of cognitive operations. Finally, we address the implications of these results for models of disease-related cognitive dysfunction and therapeutic drug development.

On the RAT task, mecamylamine produced a doserelated impairment in the acquisition of new information, although it did not impair the retrieval of old information. At this level of analysis, we cannot be certain which part(s) of the acquisition process is affected. However, mecamylamine may interfere with attending properly to reinforcement from the computer; sec- ond, the recall failure seen suggests that the ability to move information into long-term store may be reduced (i.e., that the encoding is "noisy") or that the decay of the memory trace is accelerated. Retrieval of the old chain was not substantially affected, suggesting that retrieval of well-learned information may not be mediated by the same mechanisms or that it is less vulnerable to disruption. In rats, mecamylamine has been shown to disrupt acquisition of new spatial locations more than retrieval of previously learned locations (Decker and Majchrzak 1992; Riekkinen et al. 1990).

That the acquisition process is disrupted by nicotinic blockade is further supported by the results of the Selective Reminding Task. The impairment of consistency in the elderly normals argues most strongly for an effect on transfer of information to long-term store. The effects on recall failure and total recall could also be secondary to mecamylamine's effects on attention or the encoding process. It may be that the drug has affected the "articulatory loop" subsystem of working memory (Baddeley 1992).

Effects seen on the Hi-Lo Imagery task further support the hypothesis that mecamylamine-induced difficulties encoding or transferring information into longterm store is responsible for some of the cognitive deficits seen after drug administration. Both groups showed dose-related impairment on PR measure, particularly after the delay period. In addition, the older subjects showed a significant increase in false alarms leading to a dose-related liberalization of BR. The liberalization of BR also suggests that decision-making processes have been affected (Snodgrass and Corwin 1988).

The effects on reaction time and speed suggested that mecamylamine slowed evaluation, processing, or execution time (the current configuration of our tasks does not allow independent separation of these parameters). Slowing of electroencephalographic alpha rhythm has been noted with mecamylamine (Pickworth et al. 1988), suggesting a potential effect on the efficiency of cortical processing.

The magnitude of the slowing produced by mecamylamine was small and was not of the magnitude seen with drowsiness (Newhouse et al. 1989) or antimuscarinic cholinergic antagonists such as scopolamine (Callaway et al. 1992; Wesnes and Revell 1984) suggesting that the effect was not due to nonspecific effects of sedation. The inconsistent changes in throughput on the manikin and CRT tasks may reflect the differing cognitive difficulties of the two tasks, with the manikin task having a higher cognitive load (involving spatial rotation) than the CRT, which only involves number matching.

Behavioral effects of mecamylamine in this study were minimal. Subjects blind to dosage did not report any consistent mood or anxiety changes, and they did not report any consistent physical side effects. Signifi- 
cantly, they did not show any dose-related increase in drowsiness or sleepiness. Small elevations seen on the BPRS and a few subscales were not clinically meaningful and were generally much smaller than effects seen with cognitively impairing doses of muscarinic antagonists (Sunderland et al. 1989; Newhouse et al. 1988a). No age group differences emerged.

Physiologic effects were consistent with doserelated ganglionic blockade but were more marked in the older subjects. They showed less ability to compensate for the hypotensive effects by increasing their cardiac rate and cardiac output, as evidenced by the inability of those subjects to raise pulse and sustain BP under orthostatic challenge. Older subjects showed a decline in temperature, an effect not seen in the young normals. These results suggest that aging produces increased sensitivity to ganglionic blockade, which may be a reflection of fewer peripheral nicotinic receptors or impaired compensatory mechanisms or both. The relationship between peripheral cardiovascular sensitivity and cognitive sensitivity to nicotinic antagonism remains to be further explored.

The role(s) of central nicotinic systems in cognitive operations remains the subject of considerable interest, particularly with the developing understanding of the anatomic distribution of central nicotinic receptors (Schwartz 1986; Saji et al. 1992) and their molecular biology (Luetje et al. 1990; Heinemann et al. 1991). Nicotinic receptors appear to be involved in modulating many transmitter systems but especially those involving ACh (Rowell and Winkler 1984) and dopamine (Grady et al. 1992). Although there appears to be a population of postsynaptic nicotinic receptors, many receptors may lie in a presynaptic position and modulate the release of neurotransmitters (Schwartz et al. 1984; Grady et al. 1992). For example, there appears to be a significant population of nicotinic receptors in the CA1 region of the hippocampus (Freund et al. 1990) that may interact with gamma-aminobutyric acid receptors. The effects of mecamylamine on inhibiting the transfer of information from short-term or working memory into long-term store seen in this study could be mediated in part through effects on the hippocampus (Squire and Zola-Morgan 1991).

There appears to be a tight relationship between nicotinic cholinergic receptors and dopamine systems, as evidenced by animal learning studies. The effects of mecamylamine on radial maze learning can be reversed by the dopamine $\mathrm{D}_{2}$ agonist LY 171555 (Levin et al. 1989). Impaired learning following lesions of the medial cholinergic pathway are similarly improved by the same agonist, which abolishes the mecamylamine effect (McGurk et al. 1992). Dopamine antagonists also have been shown to block the facilitatory effects of nicotine on avoidance learning (Brioni and Arneric 1993). More study will be necessary to establish whether mecamyla- mine, and by inference, nicotinic systems mediate effects on learning through dopamine systems in humans.

The interaction of nicotinic receptors with central muscarinic cholinergic receptors may be substantial, as nicotine has been shown to release $\mathrm{ACh}$, probably onto postsynaptic muscarinic receptors (Rowell and Winkler 1984; Clarke et al. 1987). Amnesia after mecamylamine administration has been correlated with decreases in regional brain $\mathrm{ACh}$ synthesis (Elrod and Buccafusco 1991). Coadministration of nicotinic and muscarinic antagonists produces supraadditive deficits on a variety of memory tasks in animals (Levin et al. 1989; Riekkinen et al. 1990). A study of combined administration of mecamylamine and scopolamine in humans (Gitelman and Prohovnik 1992) showed a greater impairment of memory scores on the Selective Reminding Task than that seen with scopolamine alone.

It is possible that some of the effects of mecamylamine may be mediated through nonnicotinic receptors. Mecamylamine is a noncompetitive antagonist that probably has its mode of action through direct blockade of the nicotinic receptor ion channel (Takayama et al. 1989). It appears that mecamylamine also interacts with other receptors that utilize ion channels, such as the N-methyl-D-aspartate (NMDA) receptor (Snell and Johnson, 1989; O'Dell and Christiansen 1988), which may be important in hippocampal function. It is possible that some effects on memory mechanisms could be mediated through actions on these receptors, although the doses of mecamylamine necessary to impair learning do not appear to block NMDA receptors (Levin 1992). The actions of NMDA receptor antagonists on animal learning do not match those of mecamylamine (Decker and Majchrzak 1992). Furthermore, in humans, the doses of the noncompetitive NMDA antagonist ketamine necessary to produce mild cognitive impairment produce profound behavioral changes similar to dissociative states and schizophrenia (Krystal et al. 1994).

These findings have implications for the understanding of the nature of the role of nicotinic systems in the cognitive deficits seen in AD and PD. These results suggest that the loss of central nicotinic receptors seen in normal aging (Court et al. 1992) and in AD and PD (Aubert et al. 1992) has functional consequences. The deficits produced by mecamylamine resemble, in several respects, those seen in AD and to a lesser extent PD. Deficits in short- and long-term memory, impaired attention, liberal bias and decreases in reaction time are hallmarks of the dementing picture seen in these disorders. The age-related nature of some of the findings suggest that the decline in nicotinic receptors with age produces increased vulnerability to the effects of nicotinic blockade. It is possible that the young subjects would have shown more cognitive im- 
pairment had the dose of mecamylamine exceeded 20 $\mathrm{mg}$. The dose range was chosen based on our estimate of doses that would be cardiovascularly tolerable to both young and old subjects. Whether this age-related cognitive vulnerability increases with progression to $A D$ or PD remains the focus of active investigation. If such sensitivity extended to AD and/or PD, enhanced vulnerability to cognitive drug impairment produced by mecamylamine might serve as an early marker of disease or a predictor of drug responsivity. This model of experimental nicotinic deficits appears to have some power to explain the derivation of some of the deficits in $A D$ and PD, particularly as the effects are not contaminated by gross behavioral or physical effects.

Finally, the results suggest that nicotinic modulation may be of benefit for the alleviation or improvements of cognitive impairments in various dementing disorders that show a loss of nicotinic receptors. Modulation of these presynaptic receptors, either through direct stimulation or allosteric modulation, may increase the activity or gain of other phasic neurotransmitter systems that may be directly responsible for the cognitive operation (Levin 1992) and may be a more effective method than direct stimulation of the postsynaptic, nonnicotinic receptor. Nicotine is unlikely to be an ideal candidate for this task, due to its low therapeutic index, but other, more selective agonists or other allosteric modulators may be useful in this regard (Lena and Changeux 1993).

\section{ACKNOWLEDGMENTS}

The authors acknowledge the invaluable contributions of Judy Kerr, R.N., Georgia Latham, M.D., Francine Kenney, Kathy Pederson, M.S., Catherine Armstrong, Elizabeth Elder, and the staff of the University of Vermont Clinical Research Center. This work was supported by NIMH Grant R29-46625 to PN, a VA Merit Review grant to JC, and by GCRCM01-00109.

\section{REFERENCES}

Aubert I, Araujo DM, Cécyre D, Robitaille Y, Gauthier S, Quirion R (1992): Comparative alterations of nicotinic and muscarinic binding sites in Alzheimer's and Parkinsons's diseases. J Neurochem 58:529-541.

Baddeley A (1992): Working memory. Science 255:556-559

Bartus R, Dean R, Beer B, Lippa A (1982): The cholinergic hypothesis of geriatric memory dysfunction. Science 217:408-417

Brandt J, Corwin C, Krafft L (1992): Is verbal recognition memory really different in Huntington's and Alzheimer's disease? J Clin Exp Neuropsychol 14:773-784

Brioni JD, Arneric SP (1993): Nicotinic receptor agonists facilitate retention of avoidance training: Participation of dopaminergic mechanisms. Behav Neural Biol 59:57-62
Buschke H, Fuld P (1974): Evaluating storage, retention, and retrieval in disordered memory and learning. Neurology 24:1019-1025

Callaway Ec, Halliday R, Naylor H (1992): Cholinergic activity and constraints on information processing. Biol Psychol 33:1-22

Clarke PBS (1987): Nicotine and smoking: A perspective from animal studies. Psychopharmacology 92:135-143

Corwin J (1992): Assessing olfaction: Cognitive and measurement issues. In Serby M, Chobor K (eds), Science of Olfaction. New York, Springer-Verlag, pp 335-354

Corwin J, Peselow E, Fieve R, Rotrosen J (1990): Disorders of decision in affective disease: An effect of $\beta$-adrenergic dysfunction? Biol Psychiat 27:813-833

CourtJA, Piggott MA, Perry EK, Barlow RB, Perry RH (1992): Age associated decline in high-affinity nicotine binding in human brain frontal-cortex does not correlate with the changes in choline-acetyltransferase activity. Neurosci Res Commun 10:125-133

Decker MW, MajchrzakMJ (1992): Effects of systemic and intracerebroventricular administration of mecamylamine, a nicotine cholinergic antagonist, on spatial memory in rats. Psychopharmacology 107:530-534

Drach man D (1977): Memory and cognitive function in man: Does the cholinergic system have a specif ic role? Neurology 27:783-790

Drachman D, Leavitt J (1974): Human memory and the cholinergic system. Arch Neurol 30:113-121

Elrod K, Buccafusco J (1991): Correlation of the amnestic effects of nicotinic antagonists with inhibition of regional brain acetylcholine synthesis in rats. J Pharmacol Exp Ther 258:403-409

Elrod K, Buccafusco J, Jackson W (1988): Nicotine enhances delayed match-to-sample performance by primates. Life Sci 43:277-281

Flynn D, Mash D (1986): Characterization of 1-[ $\left.{ }^{3} \mathrm{H}\right]$ nicotine binding in human cerebral cortex: Comparison between Alzheimer's disease and the normal. J Neurochem 47:1948-1954

Freund RK, Luntz-Leybman V, Collins AC (1990): Nicotine interferes with GABA-mediated inhibitory processes in mouse hippocampus. Brain Res 527:286-291

Fuld P, Katzman R, Davies P, Terry RD (1982): Intrusions as a sign of Alzheimer dementia: Chemical and pathological verification. Ann Neurol 11:155-159

Giacobini E (1990): Cholinergic receptors in human brain: Effects of aging and Alzheimer's disease. J Neurosci Res 27:548-560

Gitelman DR, Prohovnik I (1992): Muscarinic and nicotinic contributions to cognitive function and cortical blood flow. Neurobiol Aging 13:313-318

Grady S, Marks MJ, Wonnacott S, Collins AC (1992): Characterization of nicotinic receptor-mediated $\left[{ }^{3} \mathrm{H}\right] \mathrm{dopa}-$ mine release from synaptosomes prepared from mouse striatum. J Neurochem 59:848-856

Grober E, Buschke H, Kawas C, Fuld P (1993): Impaired ranking of semantic attributes in dementia. Brain Lang 26:276-286 
Heinemann S, Boulter J, Connolly J, Deneris E, Duvoisin R, Hartley M, Hermans-Borgmeyer I, Hollmann M, O'SheaGreenfield A, Papke R, Rogers S, Patrick J (1991): The nicotinic receptor genes. Clin Neuropharmacol 14:S45S61

Higgins ST, Woodward BM, Henningfield JE (1989): Effects of atropine on the repeated acquisition and performance of response sequences in humans. J Exp Anal Behav 51:5-15

Jones GMM, Sahakian BJ, Levy R, Warburton DM, Gray JA (1992): Effects of acute subcutaneous nicotine on attention, information processing and short-term memory in Alzheimer's disease. Psychopharmacology 108:485-494

Krystal JH, Karper LP, Seibyl JP, Freeman GK, Delaney R, Bremner JD, Heninger GR, Bowers MB, Charney DS (1994): Subanesthetic effects of the non-competitive NMDA antagonist, ketamine in humans: Psychotomimetic, perceptual, cognitive, and neuroendocrine responses. Arch Gen Psychiatry (in press)

Ksir C, Benson D (1983): Enhanced behavioral response to nicotine in an animal model of Alzheimer's disease. Psychopharmacology 81:272-273

Léna C, Changeux JP (1993): Allosteric modulation of the nicotinic acetylcholine receptor. Trends Neurosci 16:181-186

Levin ED (1992): Nicotinic systems and cognitive function. Psychopharmacology 108:417-431

Levin ED, McGurk SR, Rose JE, Butcher LL (1989): Reversal of a mecamylamine-induced cognitive deficit with the $\mathrm{D}_{2}$ agonist, LY 171555. Pharmacol Biochem Behav 33:919-922

Luetje CW, Patrick J, Seguela P (1990): Nicotine receptors in the mammalian brain. FASEB J 4:2753-2760

Martin BR, Onaivi ES, Martin TJ (1989): What is the nature of mecamylamine's antagonism of the central effects of nicotine? Biochem Pharmacol 38:3391-3397

McGurk SR, Levin ED, Butcher LL (1992): Dopaminergic drugs reverse the impairment of radial-arm maze performance caused by lesions involving the cholinergic medial pathway. Neuroscience 50:129-135

Nebes RD, Boller F, Holland A (1986): Use of semantic context by patients with Alzheimer's disease. Psychol Aging 3:261-269

Nelson JM, Goldstein L (1972): Improvement of performance on an attention task with chronic nicotine treatment in rats. Psychopharmacologia 26:347-360

Newhouse P, Sunderland T, Tariot PN (1988a): The effects of acute scopolamine in geriatric depression. Arch Gen Psychiatry 45:906-912

Newhouse $P$, Sunderland T, Tariot $P$, Blumhardt CL, Weingartner H, Mellow A, Murphy DL (1988b): Intravenous nicotine in Alzheimer's disease: A pilot study. Psychopharmacology 95:171-175

Newhouse P, Belenky G, Thomas M, Thorne D, Sing H, Fertig J (1989). The effects of $d$-amphetamine on arousal, cognition, and mood after prolonged total sleep deprivation. Neuropsychopharmacology 2:153-164

Newhouse $P$, Sunderland T, Narang P, Mellow AM, Fertig JB, Lawlor BA, Murphy DL (1990): Neuroendocrine, physiologic, and behavioral responses following intravenous nicotine in nonsmoking healthy volunteers and patients with Alzheimer's disease. Psychoneuroendocrinology 15:471-484

Newhouse P, Potter A, Corwin J, Lenox R (1992): Acute nicotinic blockade produces cognitive impairment in normal humans. Psychopharmacology 108:480-484

Nordberg A, Bergh C (1985): Effect of nicotine on passiveavoidance behavior and motoric activity in mice. Acta Pharmacol Toxicol 56:337-341

Nordberg A, Nilsson-Håkansson L, Adem A, Hardy J, Alafuzoff I, Lai Z, Herrera-Marschitz M, Winblad B (1989): The role of nicotinic receptors in the pathophysiology of Alzheimer's disease. Prog Brain Res 79:353-362

O'Dell TJ, Christensen BN (1988): Mecamylamine is a selective non-competitive antagonist of n-methyl-d-aspartateand aspartate-induced currents in horizontal cells dissociated from catfish retina. Neurosci Lett 94:93-98

Overall J, Gorham D (1962): The Brief Psychiatric Rating Scale. Psychol Rep 10:799-812

Perry EK, Perry RH, Smith CJ, Dick DJ, Candy JM, Edwardson JA, Fairbairn A, Blessed G (1987): Nicotinic receptor abnormalities in Alzheimer's and Parkinson's disease. J Neurol Neurosurg Psychiatry, 50:806-809

Pickworth WB, Herning PI, Henningfield JE (1988): Mecamylamine reduces some EEG effects of nicotine chewing gum in humans. Pharmacol Biochem Behav 30:149-153

Pomerleau C, Pomerleau O, Majchrzak M (1987): Mecamylamine pretreatment increases subsequent nicotine selfadministration as indicated by changes in plasma nicotine level. Psychopharmacology 91:391-393

Riekkinen JR, Sirvio J, Aaltonen M, Riekkinen P (1990): Effects of concurrent manipulations of nicotinic and muscarinic receptors on spatial and passive avoidance learning. Pharmacol Biochem Behav 37:405-410

Rowell PP, Winkler DL (1984): Nicotine stimulation of $\left[{ }^{3} \mathrm{H}\right]$ acetylcholine release form mouse cerebral synaptosomes. J Neurochem 43:1593-1598

Saji H, Magata Y, Yamada Y, Tajima K, Yonekura Y, Konishi J, Ohmomo Y, Yokoyama A (1992): Synthesis of (S)-N[methyl- ${ }^{11} \mathrm{C}$ ]nicotine and its regional distribution in the mouse brain: A potential tracer for visualization of brain nicotinic receptors by positron emission tomography. Chem Pharmacol Bull 40:734-736

Schwartz R (1986): Autoradiographic distribution of high affinity muscarinic and nicotinic cholinergic receptors labeled with $\left[{ }^{3} \mathrm{H}\right]$ acetylcholine in rat brain. Life Sci 38:2111-2119

Schwartz RD, Lehmann J, Kellar KJ(1984): Presynaptic nicotinic cholinergic receptors labeled by $\left[{ }^{3} \mathrm{H}\right]$ acetylcholine on catecholamine and serotonin axons in brain. J Neurochem 42:1495-1498

Snell LD, Johnson KM (1989): Effects of nicotinic agonists and antagonists on n-methyl-d-aspartate-induced ${ }^{3} \mathrm{H}$-norepinephrine release and ${ }^{3} \mathrm{H}-(1-[1-(2-$ thienyl)cyclohexyl]piperidine): binding in rat hippocampus. Synapse 3:129135

Snodgrass J, Corwin J (1988): Pragmatics of recognition memory: Application to dementia and amnesia. J Exp Psychol 117:34-50 
Squire LR, Zola-Morgan S (1991): The medial temporal lobe memory system. Science 253:1380-1386

Stolerman I, Goldfarb T, Fink R, Jarvik M (1973): Influencing cigarette smoking with nicotine antagonists. Psychopharmacology 28:247-259

Sunderland T, Tariot PN, Newhouse PA (1989): Differential responsivity of mood, behavior, and cognition to cholinergic agents in elderly neuropsychiatric populations. Brain Res Rev 13:371-389

Takayama H, Majewska MD, London ED (1989): Interactions of noncompetitive inhibitors with nicotinic receptors in the rat brain. J Pharmacol Exp Ther 253:1083-1089

Thompson D (1973): Repeated acquisition as a behavioral base line for studying drug effects. J Pharmacol Exp Ther 184:506-514

Thorne D, Genser S, Sing H, Hegge F (1985): The Walter Reed performance assessment battery. Neurobehav Toxicol Teratol 7:415-418

Van Kammen D, Murphy D (1975): Attenuation of the euphoriant and activating effects of $d$ - and $l$-amphetamine by lithium carbonate treatment. Psychopharmacology 44:215-224
Weingartner H, Cohen R, Sunderland T, Tariot P, Thompson K, Newhouse P (1987): Diagnosis and assessment of cognitive dysfunctions in the elderly. In Melzer H (ed), Psychopharmacology: The Third Generation of Progress. New York, Raven Press, pp 909-919

Wesnes K, Warburton D (1983): Smoking, nicotine, and human performance. Pharmacol Ther. 21:189-208

Wesnes K, Revell A (1984): The separate and combined effects of scopolamine and nicotine on human information processing. Psychopharmacology 84:5-11

Whitehouse PJ, Price DL, Struble RG, Clark AW, Coyle JT, De Long MR (1982): Alzheimer's disease and senile dementia-loss of neurons in the basal forebrain. Science 215:1237-1239

Whitehouse PJ, Martino A, Antuono P, Kellar K (1986): Nicotinic acetylcholine binding sites in Alzheimer's disease. Brain Res 371:146-151

Vitaliano PP (1982): Parametric statistical analysis of repeated measures experiments. Psychoneuroendocrinology $7: 3-13$ 